\title{
Currency Substitution and the Stability of the Italian Demand for Money before the entry into the Monetary Union, 1972-1998*
}

\author{
Hannah Nielsen† Giuseppe Tullio
}

July 2000

\begin{abstract}
A money demand function for M2 is estimated for Italy for the period 1972-1998 within an error correction framework. This period has been characterized by major structural changes in the Italian financial system and by major changes in monetary policy. This study takes these changes into account. Moreover, currency substitution, especially between Italy and Germany is incorporated into the model. By accounting for structural breaks and currency substitution a stable money demand function can be found.
\end{abstract}

Key words: Money demand; error correction model; structural changes JEL classification: $\mathrm{E} 41, \mathrm{C} 22$

*Financial support from the Deutsche Forschungsgemeinschaft, SFB 373, is gratefully acknowledged. We thank Uwe Hassler, FU Berlin, and Carsten Trenkler, SFB 373, for helpful comments.

${ }^{\dagger}$ FU Berlin, Institut für Statistik und Ökonometrie, Sonderforschungsbereich 373, Boltzmannstr. 20, D-14195 Berlin, Germany, e-mail: hannahni@wiwiss.fu-berlin.de

${ }^{\ddagger}$ Luiss University, OCSM, Viale Pola 12, I-00198 Roma, Italy, e-mail: gtullio@altavista.net

${ }^{\S}$ FU Berlin and DIW, Institut für Statistik und Ökonometrie, Boltzmannstr. 20, D14195 Berlin, Germany, e-mail: wolters@wiwiss.fu-berlin.de 


\section{Introduction}

The primary goal of the European Central Bank is to maintain price stability. One of the 'two pillars' for achieving this goal is the control of the development of broad money M3 in the euro area. Therefore many studies exist concerning the empirical implementation of money demand for M3 in the euro area, see e.g. Coenen And Vega (1999) or Hayo (1999).

But all these empirical work has to use pre-EMU data from the different countries now forming 'Euroland'. The implicit assumption then is that past data give reliable information for monetary policy in EMU, that is, there exists a behavioral persistence. To see, whether this is really the case, it is important to analyze also money demand functions for the individual countries for the pre-EMU period. Therefore we will investigate money demand for Italy, one of the larger countries, and what is especially interesting in this case, with a lot of institutional changes in the pre-EMU era.

During the time from 1972 to 1998 Italian monetary policy and the Italian financial system underwent major structural changes. ${ }^{1}$

The seventies were characterized by high inflation and large budget deficits. With the Total Domestic Credit (CTI) as intermediate target economic growth and employment were promoted rather than the stability of prices and of the currency. Italy was isolated from foreign money markets due to extensive controls on capital movements and foreign exchange transactions. In addition, bank lending was regulated by portfolio constraints and credit ceilings.

At the beginning of the eighties the Banca d'Italia started to gain monetary policy independence from the fiscal authorities. A decisive event in this respect was the so called 'divorce' of the Banca d'Italia and the Treasury in July 1981, which freed the central bank from the obligation to intervene and act as residual buyer at the government securities auctions. From 1992 on the choice of the discount rate became the sole decision of the central bank and the Treasury was no longer allowed to borrow from the Banca d'Italia.

\footnotetext{
${ }^{1}$ See e.g. Fratianni and Spinelli (1997).
} 
A further important point is the switch from CTI to M2 as intermediate target, which took place between 1983 and 1984 and documented the aim to implement a long-run monetary policy with the main focus on price stability. During the second half of the eighties the quantitative constraints were gradually lowered and the monetary isolation from abroad was removed. Also during that time a lot of innovations concerning financial products and markets were introduced, which caused structural changes in the money market.

Besides the internal challenges Italian monetary policy had to face external constraints arising from its partnership in the European Monetary System (EMS). Italy was in the EMS from the beginning in 1979, but with a wider band than the other members $( \pm 6 \%)$. In 1990 the band was reduced to the 'standard' band of $\pm 2.25 \%$. Before 1983 the Exchange Rate Mechanism (ERM) was rather flexible with frequent realignments. After 1983 the regime became quasi fixed. Due to credibility problems, a loss of competitiveness and the unability to lower the budget deficit the Italian Lira left the ERM in September 1992, rejoining it in November 1996, this time with the new very wide band of $\pm 15 \%$ introduced in August 1993. Italy is now also a member of 'Euroland'.

Although the transition took place over an extended period the year 1983 works well as break point between the two fairly different regimes. Some studies concerning the Italian money demand split their samples at this point and examine two different periods (see for example AngELINI ET AL. (1994) or Juselius (1998)) or take the year 1983 as beginning of the sample (Fanelli And Paruolo (1999) or Rinaldi And Tedeschi (1996)).

The existing literature regarding the Italian money demand contains many different approaches. SARno (1999) and Muscatelli And SPINELli (1996, 2000) use historical annual data covering the period from 1861 to 1991, 1861 to 1990 and 1861 to 1996, respectively. Working with single-equation estimation methods they detect one cointegrating relationship. Also applying a single equation model, but for the samples 1975-1979 and 1983-1991 and using monthly as well as quarterly data, is the work of ANGELINI ET 
AL. (1994). They estimate a money demand function by allowing for different scale variables (net financial assets and domestic demand) within the two subperiods. Also a single-equation approach is used by BAGLIANO AND FAVERo (1992), who specifiy a feedback and a feedforward model for quarterly data for the sample 1964-1986. Muscatelli AND PAPI (1990) model the process of financial innovation in a nonlinear way. They find one significant cointegration relation, estimating then an error correction model for quarterly data for the period 1963-1987.

Another approach is used by Gennari (1999), Bagliano (1996), RINALDi AND TEDEschi (1996) and Juselius (1998), who assume that more than one cointegration relationship exists and therefore implement a multivariate framework. They identify three (BAGLiAno (1996) finds two) cointegrating vectors, one of them being the money demand relationship.

What has not been taken into consideration by the previous literature is the effect of currency substitution. That effects of currency substitution should not be neglected has been made evident for instance by SEITZ AND Reimers (1999) or Deutsche Bundesbank (1995). They show that there are significant substitution effects between the Italian Lira and the DM.

In this paper we are concerned with a structural demand function for broad money. In contrast to the existing literature we (i) use data for the whole period from 1972 to 1998, trying to find explanatory variables for the structural changes within this time span, so there is no need to split the sample and,

(ii) since currency substitution has not been taken into account so far, we will test for its presence through US Dollar/Lira and DM/Lira exchange rates and a German interest rate.

This paper is organized as follows. Section 2 contains a preliminary analysis of the data. In section 3 we specify and estimate a long-run money demand relation and use this in an error correction model for real money balances. Stability tests show that it is possible to find a stable money demand equation for the whole period from 1972(1) to 1998(3). Section 4 presents conclusions. 


\section{The Data and Preliminary Analysis}

In the money demand literature there is a general agreement that a long run money demand relation for real balances should include a scale variable such as real gross national product (GNP); this is motivated by the fact that money is used for transaction purposes. Moreover, the rate of interest and inflation are used as explanatory variables to capture opportunity costs of holding money. For a broad monetary aggregate it is also important to include the own rate of return on money. As to Italy, also currency substitution seems to have been significant, see e.g. SEITz And Reimers (1999). Currency substitution has been modelled ${ }^{2}$ through foreign interest rates, the forward discount, the rate of change of the nominal exchange rate and the nominal exchange rate.

Nominal money balances $\mathrm{M}^{3}$, the Italian and German bond yields are taken from $\mathrm{IMF}^{4}$, the own rate of $\mathrm{M} 2$ and GNP at current prices are from Banca d'Italia. The GDP deflator P, the Lira/US Dollar exchange rate and Lira/DM exchange rate have been taken from the $\mathrm{OECD}^{5}$. All data with the exception of $\mathrm{P}$ are seasonally unadjusted. All variables are in logarithms with the exception of the interest rates. $m_{t}$ denotes the logarithm of the real money stock M2 at time $t, y_{t}$ is the logarithm of real GNP, $r_{t}\left(r_{t}^{D}\right)$ is the long-term Italian (German) interest rate and $r_{t}^{o}$ the own rate on M2 in decimals. The annual inflation rate $\pi_{t}$ is defined as the fourth's differences of $\log \mathrm{P}$ also in decimals. The logarithm of the Lira/US Dollar (Lira/DM) exchange rate is denoted as $e_{t}^{U S}\left(e_{t}^{D}\right)$. The estimation period ranges from 1972(1) to 1998(3). The variables are depicted in Figure 1. $m_{t}$ shows the most unstable behaviour. There seems to be a break in the data around 1983, which could be associated to the structural changes described above. Moreover a further break is observed in 1995/1996, which could be seen as a

\footnotetext{
${ }^{2}$ See Tullio ET Al. (1996).

${ }^{3} \mathrm{M} 2$ contains notes and coins, current account deposits, postal savings deposits, savings deposits and bank certificates of deposits for terms of less than 18 months.

${ }^{4}$ IMF: $13639 \mathrm{M}, 13661$, and 13461 , respectively.

${ }^{5}$ OECD, national accounts: $161051 \mathrm{KSA}, 167005 \mathrm{D}$, and $127005 \mathrm{D}$, respectively. The exchange rates are expected values, that means that the series are shifted forward for one quarter. 
result of the depreciation of the Lira at the beginning of 1995 (DIW (2000)). For $y_{t}$ the seasonal pattern has changed after 1994 . The inflation rate $\pi_{t}$ very clearly shows the Italian success in fighting inflation to meet the Maastricht criteria. The exchange rate $e_{t}^{D}$ obviously shows that Italy left the ERM in $1992(3)$.

Applying augmented Dickey-Fuller unit root tests as well as Perron unit root tests allowing for breaks in the constant and/or the trend parameter leads to the result that all time series can be treated as integrated of order one, I(1). ${ }^{6}$ That means the levels of the variables show nonstationary behaviour, but the first differences are stationary. Therefore, the next step in our analysis is an investigation of the cointegration properties of the variables $m_{t}, y_{t}, r_{t}, r_{t}^{o}, r_{t}^{D}, \pi_{t}, e_{t}^{U S}, e_{t}^{D}$. That means we investigate whether linear combinations of all or subsets of these nonstationary variables exist which are stationary. Such stationary linear combinations can very often be interpreted as long-run economic relations. Here we are especially interested in finding a long-run money demand relation.

We applied JoHANSEn's (1995) maximum likelihood approach for the whole period. Due to the presumed break in $m_{t}$ around 1983, we include a step dummy $S 83 q 1_{t}$, which is one starting with 1983(1) and zero before. The test is performed within a vector error correction model of order one, which was chosen following the Schwarz information criterion, allowing for a linear deterministic trend and including centered seasonal dummies. Since dummy variables as $S 83 q 1_{t}$ influence the asymptotic distribution of the likelihood-ratio test statistic for the cointegration rank we have used the program DisCo (see Johansen AND Nielsen, 1993) to simulate critical values for this particular case. The likelihood-ratio test indicates that there exist three cointegrating relations, which would be consistent with the results found by Gennari (1999), Rinaldi And Tedeschi (1996) and Juselius (1998). Using a 5\% significance-level, the hypothesis of a cointegration rank of zero, one and two can be clearly rejected, while a rank of three cannot be rejected, even if the usual critical values are considered.

\footnotetext{
${ }^{6}$ All computations are done with EVIEws 3.1.
} 
Figure 1: The time series used
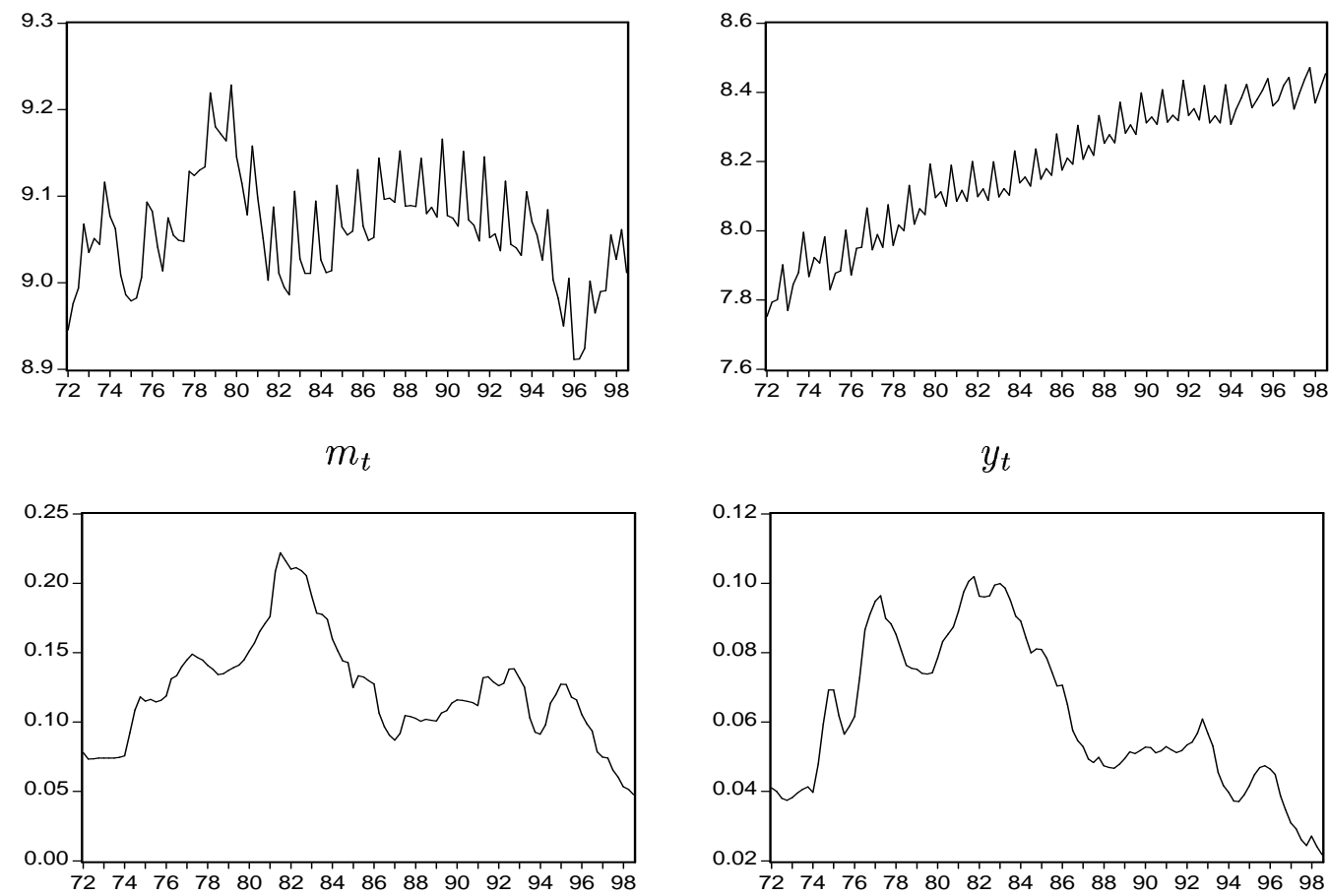

$r_{t}$

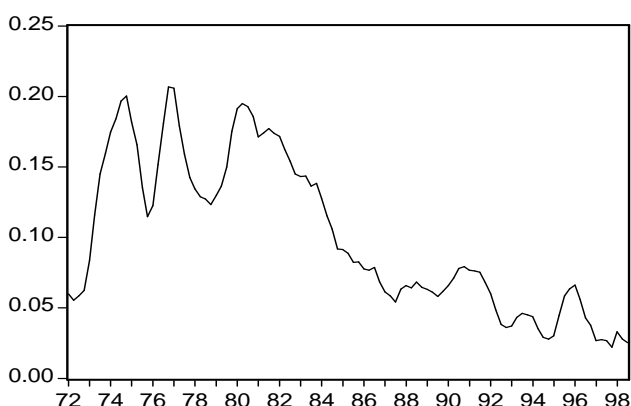

$\pi_{t}$

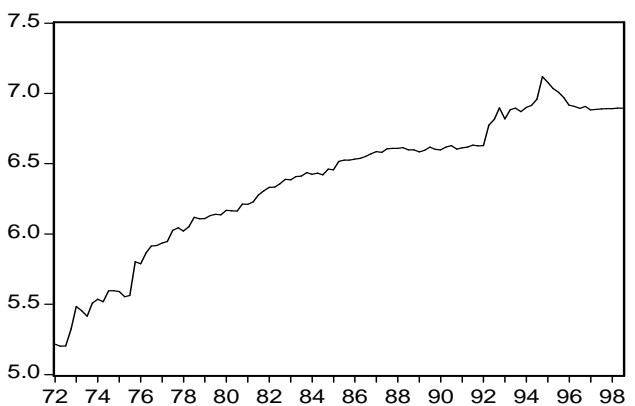

$e_{t}^{D}$

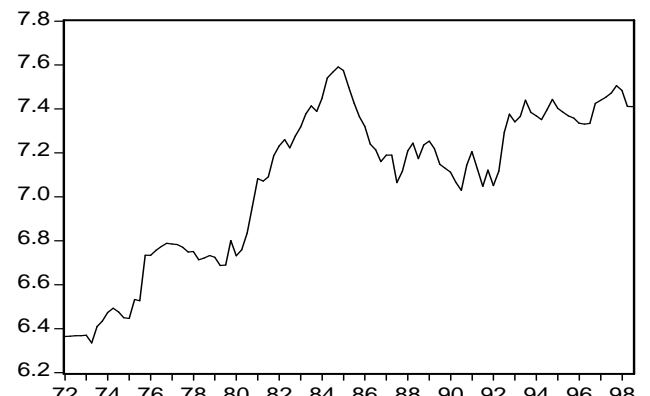

$$
e_{t}^{U S A}
$$




\section{Specification and Estimation of a Money Demand Function}

Due to all the structural changes in the Italian monetary system we do not try to model a money demand equation within this high-dimensional vector error correction model, but use instead a single equation approach to gain more flexibility for specifying the various changes which took place during the period under observation. Moreover, in monetary policy very often single equations are preferred, because they are easier to understand and interpret.

We use the ENGLE-Granger (1987) approach to estimate a long-run money demand function. Due to the structural changes around 1983, especially the switch from CTI to M2 as intermediate target we include the shift dummy $S 83 q 1_{t}$ described above. The Lira/DM exchange rate is included only after 1992, when Italy left the ERM and the exchange rate was not restricted to stay within the given band. Thus, $e_{t}^{D}$ is multiplied by the shift dummy $S 92 q 1_{t}$, which is zero before 1992(1) and one after. Finally, this estimation approach leads to the following specification (standard errors are given in parantheses beneath the estimated coefficients):

$$
\begin{aligned}
& m_{t}=\underset{(0.51)}{4.35}+\underset{(0.07)}{0.62} y_{t}-\underset{(0.20)}{1.04 r_{t}}+\underset{(0.87)}{5.84}\left(S 83 q 1_{t} \cdot r_{t}^{o}\right)-\underset{(0.48)}{2.17}\left(S 83 q 1_{t} \cdot \pi_{t}\right) \\
& -\underset{(0.32)}{0.83 r_{t}^{D}}-\underset{(0.002)}{0.020}\left(S 92 q 1_{t} \cdot e_{t}^{D}\right)-\underset{(0.06)}{0.32} S 83 q 1_{t}+\hat{z}_{t} \\
& \bar{R}^{2}=0.60 \quad S E=0.039 \quad J B=0.25(0.88) \\
& T=107 \quad[1972(1)-1998(3)] \text {. }
\end{aligned}
$$

Since all variables are $\mathrm{I}(1)$ the usual $t$-distribution cannot be applied. To achieve standard inference we use the modification suggested by SAIKKONNEN (1991). Equation (1) is augmented by lags and leads of order $-K$ to $K$ of the differences of all regressors. It turned out that $K=1$ was sufficient. To obtain correct $t$-values the OLS $t$-ratios of the augmented equation are multplied with the ratio of the residual variance of $\hat{z}_{t}$ to the long-run variance of $\hat{z}_{t}$. All coefficients in (1) are significantly different from zero at least at the $5 \%$-level, except $r_{t}$, which is significant at the $10 \%$-level. 
For the Jarque-Bera (JB)-test the $p$-value is given in parantheses. This statistic is computed to test if the residuals are normally distributed. Looking at the $p$-value of 0.88 the null hypothesis of normally distributed residuals cannot be rejected.

The residuals $\hat{z}_{t}$ of regression (1) were tested for cointegration by applying the augmented Dickey-Fuller unit root test. The null hypothesis of no cointegration implies that $\hat{z}_{t}$ is $\mathrm{I}(1)$, whereas the alternative hypothesis of cointegration implies that $\hat{z}_{t}$ is stationary. The resulting $t$-statistic amounts to -5.19 . The critical values, which are tabulated by MAcKinnon (1991) only include the case of five nonstationary regressors, whereas here we have to deal with six I(1)-variables as regressors and a shift dummy. Therefore we use simulated critical values including six independent nonstationary regressors and a shift dummy. ${ }^{7}$ The critical values are -5.36 (5\%-level) and -5.04 (10\%-level) respectively, so it can be concluded that $\hat{z}_{t}$ is stationary at least at the 10\%-level, therefore equation (1) forms a cointegration relation.

The actual and fitted values as well as the residuals $\hat{z}_{t}$ are depicted in Figure 2. It seems that the break in 1983 is very well captured by our specification. But it also can be seen that there are some turbulences at the end of the sample, around 1995/1996.

Figure 2: Residuals of the static regression (1)

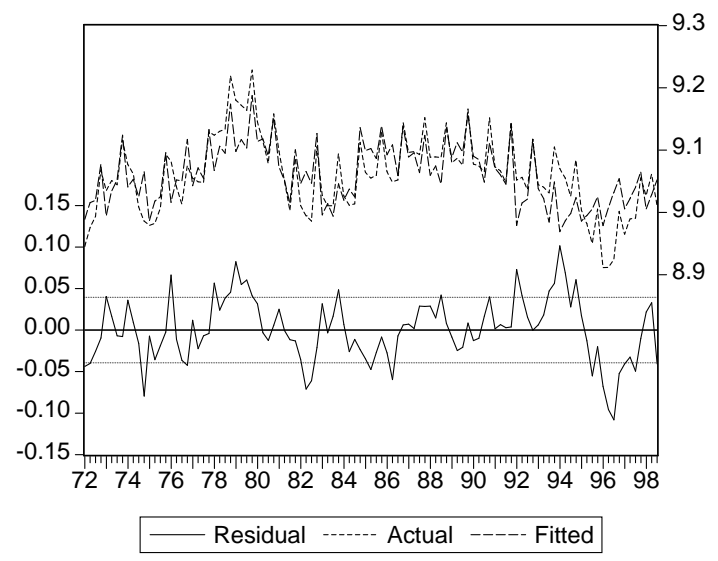

\footnotetext{
${ }^{7}$ The critical values have been simulated using a sample size of 100 and 10000 replications. The shift dummy is included in the last $60 \%$ of the sample. We thank UWE HASSLER for making his program available to us. See also HAssLer (2000).
} 
All coefficients in the long-run money demand equation (1) show the signs which are postulated by economic theory. The income elasticity of 0.62 is clearly smaller than one and more in the neighbourhood of an income elasticity of 0.5 , predicted by the BAUMOL-TOBIN framework. The coefficients of $r_{t}, r_{t}^{o}, \pi_{t}$ and $r_{t}^{D}$, are semielasticities. Assuming a long-term Italian rate of $12 \%$ leads to an interest elasticity of $-0.12(=-1.04 \cdot 0.12)$. Assuming a $5 \%$ rate for $r_{t}^{o}, \pi_{t}$ and $r_{t}^{D}$ leads to elasticities of $0.29,-0.11$ and -0.04 respectively. Moreover, important variables in a money demand equation as the own rate of money and the inflation rate are only effective since 1983 after the 'divorce' and the use of M2 as intermediate target. The results further show that currency substitution, modelled by the German long-term interest rate plays an important role during the whole period. After 1992(1), when the Italian Lira left the ERM we also found a significant influence of the Lira/DM exchange rate, whereas the Lira/US Dollar exchange rate does not contribute significantly to the performance of the regression and has therefore not been included. If we would exclude $S 92 q 1_{t} \cdot e_{t}^{D}$ from equation (1), we would not be able to model the break in M2 in 1995 and 1996 in a satisfactory manner. Thus, currency substitution with regard to Germany is even stronger since Italy left the ERM.

The specification of an error correction model (ecm) is the next step in our analysis. Following the Engle-Granger procedure the lagged residuals $\hat{z}_{t-1}$ resulting from the static regression (1) are used as error correction term within the error correction equation. We allow for up to four lags for the changes of the variables and include $\Delta S 83 q 1_{t}, I 74 q 4_{t}$ (which is one for 1974(4) and zero elsewhere) as well as seasonal dummies $d_{i t}, i=1,2,3 . I 74 q 4_{t}$ is used according to JusELIUs (1998) since there was a sharp decline in the money stock and real GDP induced by very tight fiscal policy and the introduction of quantitative restrictions on bank lending. Successively eliminating the variables with the lowest $t$-values results in the following specification ( $t$-statistics are given in parantheses beneath the estimated coefficients): 


$$
\begin{aligned}
& \Delta m_{t}=\underset{(-4.57)}{0.21} \hat{z}_{t-1}+\underset{(2.05)}{0.16} \Delta m_{t-1}+\underset{(4.82)}{0.35} \Delta m_{t-4}-\underset{(-3.15)}{0.25} \Delta y_{t-1}-\underset{(-2.43)}{0.18} \Delta y_{t-2} \\
& -\underset{(-2.26)}{0.18} \Delta y_{t-4}-\underset{(-2.17)}{0.25} \Delta\left(S 83 q 1_{t} \cdot \pi_{t}\right) \\
& +\underset{(6.67)}{0.074}-\underset{(-5.46)}{0.12} d_{1 t}-\underset{(-5.14)}{0.068} d_{2 t}-\underset{(-6.19)}{0.095} d_{3 t}-\underset{(-5.14)}{0.090 I 74 q 4_{t}}+\hat{u}_{t} \\
& \bar{R}^{2}=0.89 \quad \mathrm{SE}=0.017 \quad \mathrm{JB}=0.67(0.71) \\
& \operatorname{LM}(1)=1.25(0.27) \quad \operatorname{LM}(4)=0.55(0.70) \quad \operatorname{LM}(8)=0.60(0.78) \\
& \operatorname{ARCH}(1)=1.64(0.20) \quad \operatorname{ARCH}(4)=0.99(0.41) \quad \operatorname{RESET}(1)=7.74(0.01) \\
& \mathrm{T}=106[1972(2)-1998(3)]
\end{aligned}
$$

For the test statistics the $p$-values are given in parantheses. The diagnostic tests indicate that the model is well specified. The assumption of normally distributed residuals cannot be rejected (JB). Lagrange multiplier (LM) tests of no error autocorrelation against autocorrelation of at most order $k=1,4,8$ do not indicate any problems concerning autocorrelated residuals. The model also passes the LM tests against conditional heteroskedasticity $(\mathrm{ARCH}(k))$ of at most order $k=1,4$. Only the RESET(1)-test leads to the assumption that there may be some kind of nonlinearity. The $t$-statistic of the error correction term amounts to -4.57 , which can again ensure the existence of a cointegration relationship. Moreover, the negative sign of the coefficient shows that the adjustment process leads into the right direction, that means excess money is followed in the next period by a reduction of the money stock.

The stability of the estimated equation has been checked using the CUSUMtest, the CUSUM of squares-test, the plot of the recursive residuals, and the plot of the recursive estimates of the coefficient of the error correction term $\hat{z}_{t-1}$ in equation (2). ${ }^{8}$ All these results are shown in Figure 3. (For the CUSUM- and CUSUM of squares-test the $5 \%$ critical lines, for the recursive residuals and estimates the two-standard-error bands are shown.)

\footnotetext{
${ }^{8}$ Since $\Delta\left(S 83 q 1_{t} \cdot \pi_{t}\right)$ is zero before $1983(1)$ we generated a white noise process with zero mean and a variance of 0.00001 for 1972(2)-1982(4) to be numerically able to compute the recursive estimates from the beginning.
} 
The CUSUM- and the CUSUM of squares test do not indicate any instability of the estimated equation. By examining the plot of the recursive residuals only three values which lie not very far outside the two-standarderror bands can be noticed. The recursive estimate of the coefficient of the error correction term in equation (2) also shows no significant instability. Thus a stable money demand equation seems to exist in Italy for the period 1972 to 1998.

Figure 3: Stability analysis

\section{CUSUM-test}

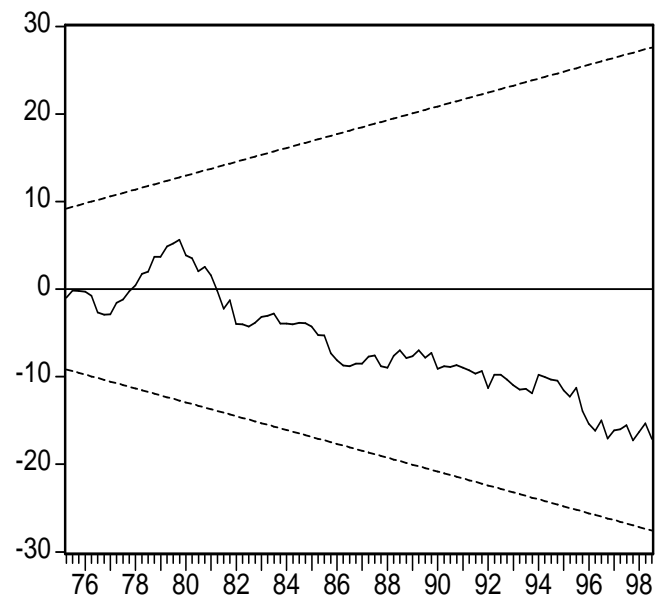

Recursive residuals

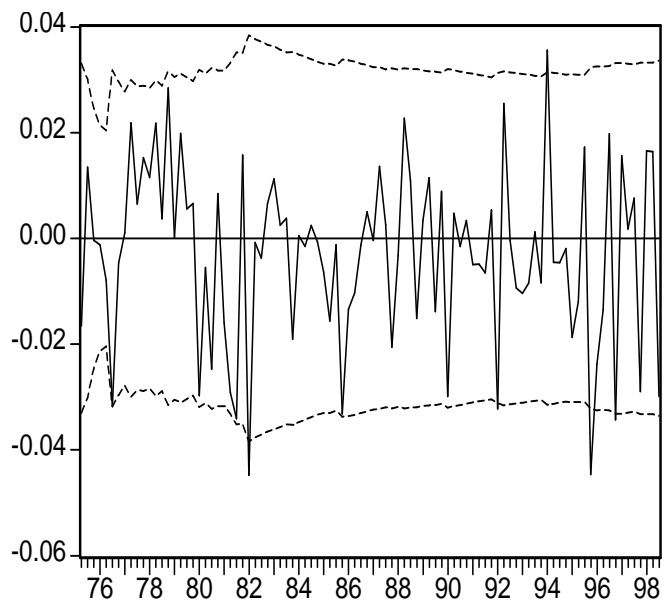

CUSUM of squares-test

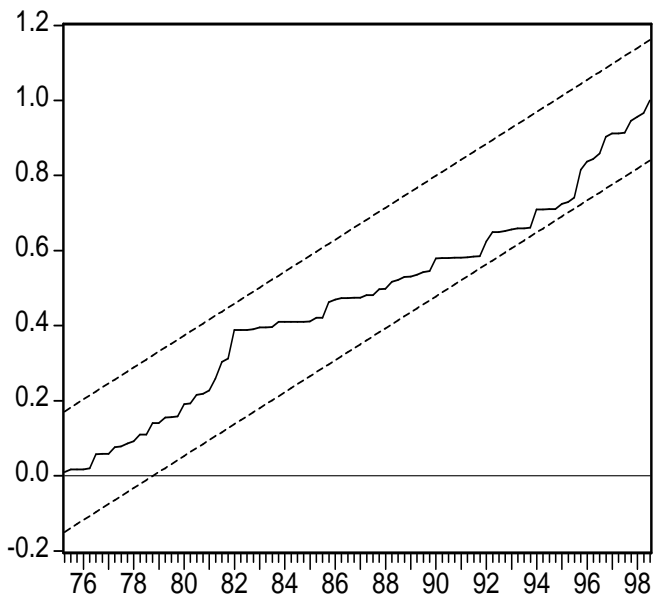

Coefficient of $\hat{z}_{t-1}$ in eq. (2)

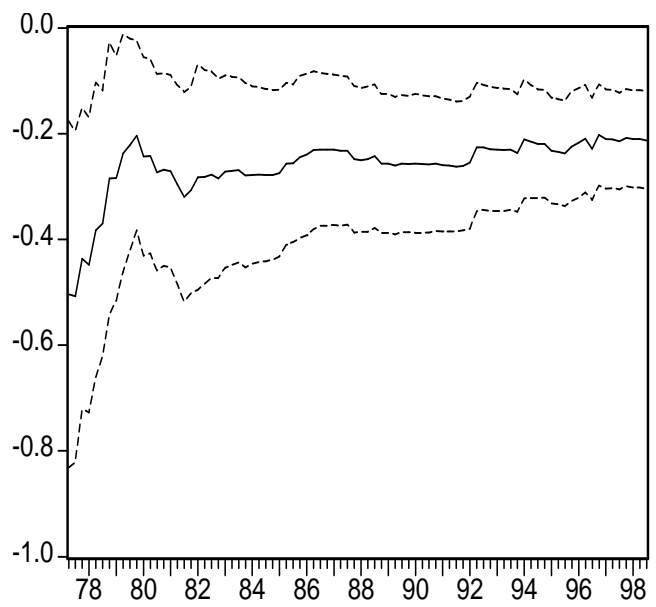




\section{Conclusions}

The period from 1972 to 1998, here under observation, is characterized by major institutional changes in the design of Italian monetary policy and in the financial system. Despite this fact we are able to detect a stable money demand function for the whole period by using the Engle-Granger approach. We estimate the long-run relation as well as the short-run dynamics through an error correction model. What has been evident is the influence of currency substitution, especially between Italy and Germany, which has been taken into account by the Lira/DM exchange rate and a German interest rate. Especially the Lira/DM exchange rate enables us to model the structural break in 1995 and 1996 in M2. Other studies concerning the Italian money demand do not consider currency substitution and do not include the whole sample and especially the recent data. One corollary of the relevance of currency substitution found by us is that Italian monetary policy may have exacerbated the depreciation of the currency in 1994-1995, when the money stock was not growing (or growing very little) and money demand was falling by more.

The estimated magnitude of the income elasticity (0.62) is comparable to the results found by Angelini ET AL. (1994) or BAgliano (1996). AnGELINI ET AL. (1994) estimate an elasticity to domestic demand of around 0.6 , depending on the frequency of the data and an elasticity of the own rate of money that is higher than the one of the alternative yield, a result which also holds in our case. The income elasticity found by BAgLiAnO (1996) amounts to about 0.8, depending on the different estimation techniques. These empirical results are also consistent with the BAUMOL-TOBIN framework or with the development of close substitutes to M2 in the Italian financial system.

It seems that in the period, we are concerned with, the monetary aggregate M2 fulfills the necessary conditions to be used as an intermediate target for Italian monetary policy. 


\section{References}

[1] Angelini, P., D. Hendry and R. Rinaldi. (1994), An Econometric Analysis of Money Demand in Italy. Temi di discussione del Servizio Studi, Banca d'Italia, 219.

[2] Bagliano, F. (1996), Money Demand in a Multivariate Framework: A System Analysis of Italian Money Demand in the '80s and Early '90s. Economic Notes, 25, 425-464.

[3] Bagliano, F. and C. Favero. (1992), Money demand instability, expectations and policy regimes: A note on the case of Italy: 1964-1986. Journal of Banking and Finance, 16, 331-349.

[4] Coenen, G. and J.-L. Vega. (1999), The Demand for M3 in the Euro Area. Working Paper, European Central Bank, No. 6.

[5] DIW (2000), Konsolidierung, Konvergenz und Reformen - Entwicklung und Perspektiven der italienischen Wirtschaft. Wochenbericht, Vol. 67, No. 11, 154-159.

[6] Deutsche Bundesbank (1995), Demand for Money and Currency Substitution in Europe. Monthly Report, Vol. 47, No. 1, 33-49.

[7] Engle, R. and C. Granger. (1987), Co-Integration and Error Correction: Representation, Estimation, and Testing. Econometrica, 55, 251-276.

[8] Fanelli, L. and P. Paruolo. (1999), New evidence on the transmission mechanism of monetary policy in Italy before Stage III of EMU. mimeo, University of Bologna.

[9] Fratianni, M. and F. Spinelli. (1997), A Monetary History of Italy. Cambridge University Press, Cambridge.

[10] Gennari, E. (1999), Estimating Money Demand in Italy 1970 - 1994. Working Paper, European University Institute, No. 99/7.

[11] Hassler, U. (2000), Dickey-Fuller Cointegration Test in the Presence of Regime Shifts at Known Time. mimeo.

[12] Hayo, B. (1999), Estimating a European Demand for Money. Scottish Journal of Political Economy, 46, 221- 244. 
[13] Johansen, S. (1995), Likelihood-Based Inference in Cointegrated Vector Autoregressive Models. Oxford University Press, Oxford.

[14] Johansen, S. and B. Nielsen. (1993), Manual for Simulation Program DisCo. Institute of Mathematical Statistics, University of Copenhagen.

[15] Juselius, K. (1998), Changing monetary transmission mechanisms within the EU. Empirical Economics, 23, 455-481.

[16] MacKinnon, J. (1991), Critical Values for Cointegration Tests. In: Engle, R. und C. Granger (eds.): Long-Run Economic Relationships, Oxford University Press, Oxford, 267-276.

[17] Muscatelli, V. and L. Papi. (1990), Cointegration, Financial Innovation and Modelling the Demand for Money in Italy. The Manchester School, $58,242-259$.

[18] Muscatelli, V. and F. Spinelli. (1996), Modelling Monetary Trends in Italy using Historical Data: The Demand for Broad Money 1861-1990. Economic Inquiry, 34, 579-596.

[19] Muscatelli, V. and F. Spinelli. (2000), The long-run stability of the demand for money: Italy 1861-1996. Journal of Monetary Economics, 45, 717-739.

[20] Rinaldi, R. and R. Tedeschi. (1996), Money Demand in Italy: A System Approach. Temi di discussione del Servizio Studi, Banca d'Italia, 267.

[21] Saikkonen, P. (1991), Asymptotically Efficient Estimation of Cointegration Regressions. Econometric Theory, 7, 1-21.

[22] Sarno, L. (1999), Adjustment Costs and Nonlinear Dynamics in the Demand for Money: Italy, 1861 - 1991. International Journal of Finance and Economics, 4, 155-177.

[23] Seitz, F. and H.-E. Reimers. (1999), Currency Substitution: A Theoretical and Empirical Analysis for Germany and Europe. The Manchester School of Economic and Social Studies, 67, 137-153.

[24] Tullio, G., E. de Souza und P. Giucca. (1996), The Demand for Money Functions in Europe and in Germany before and after the Fall of the Berlin Wall. In: P. DeGrauwe, S. Micossi und G. Tullio (Hrsg.): Inflation and Wage Behaviour in Europe, Clarendon Press, Oxford, 310-338. 